\title{
Bipolar disorders in ICD-11: current status and strengths
}

Jules Angst ${ }^{1 *}$, Vladeta Ajdacic-Gross ${ }^{1}$ and Wulf Rössler ${ }^{1,2,3}$

\begin{abstract}
Background: The Clinical descriptions and diagnostic guidelines for the ICD-11 Classification of mental and behavioural disorders should soon be finalized. To measure their potential impact, the new proposed definitions of bipolar disorders in ICD-11 were applied to data from the Zurich cohort study and compared with the definitions of ICD-10 and DSM-5.

Results: We found little difference between ICD-11 and ICD-10 in the identification of subjects with bipolar disorders, but compared to DSM-5 a considerable increase in the diagnosis of hypomanic episodes and therefore of bipolar-II disorders.

Conclusions: Compared to ICD-10 and DSM-5 the definition of hypomanic episodes according to ICD-11 represents important progress. A higher prevalence of BP-II disorder makes sense from a clinical point of view. Further transcultural research is needed into whether out-patient treatment should be included as a criterion for hypomania. Pure mania is unfortunately missing as an independent and codable disorder in the international diagnostic manuals, whether ICD-11 or DSM-5.
\end{abstract}

Keywords: Bipolar, ICD-10, ICD-11, DSM-5

\section{Introduction}

The World Health Organization is central to the continuous development of the diagnostic classification of medical disorders. With the ICD-11 officially approved, the next stage in our field will be the publication of the Clinical Descriptions and Diagnostic Guidelines (CDDG) for the manual's Mental and Behavioural Disorders section. The guidelines are currently out for consultation and comment. From 2022 the ICD-11 should be in worldwide use. The ICD review process has taken over ten years, partly overlapping with the fifth revision of the DSM of the American Psychiatric Association, which was completed in 2013. From the outset the general aim was to harmonise their structure and descriptions in order to avoid arbitrary differences (Reed et al. 2019).

\footnotetext{
*Correspondence: jules.angst@uzh.ch

${ }^{1}$ Department of Psychiatry, Psychotherapy and Psychosomatics,

Psychiatric Hospital, University of Zurich, Zurich, Switzerland

Full list of author information is available at the end of the article
}

Differences persist nonetheless. In its conception the ICD-11 is guided by the principles of clinical usefulness and global applicability. In particular, its descriptions of the "essential features" of mood episodes are not presented as equivalents of strict diagnostic criteria. Symptom counts or duration cut-offs are generally avoided, which is designed to reflect clinical practice and the exercise of clinical judgment. A full account of the changes in ICD-11 and their rationale is to be found in (Reed et al. 2019).

The purpose of this short paper is to compare the definitions of manic and hypomanic episodes in ICD-11 (as it currently stands) (a) briefly with the previous version ICD-10 (World Health Organization 1992) and (b) with DSM-5 of the American Psychiatric Association (American Psychiatric Association 2013). By applying the criteria to data from the Zurich study, described in detail in an earlier publication (Angst et al. 2016), we can provisionally illustrate some consequences of the revisions. 


\section{Zurich study sample and definitions}

The Zurich study is an epidemiological study, which followed the probands over a period of 30 years from the ages of $19 / 20$ to $49 / 50$. The interview sample was selected from an initial cohort of 4547 people $(\mathrm{f}=2346 ; \mathrm{m}=2201)$ representative of the canton of Zurich in Switzerland, who were screened in 1978 by the Symptom Checklist 90 (SCL-90-R) (Derogatis 1977) when they were 19 years old (males) or 20 years old (females).

To increase the probability of the development of psychiatric syndromes, a stratified sub-sample of 591 subjects was selected for the longitudinal study. Two-thirds of the sample consisted of high scorers (defined as scoring above the 85th percentile of the global severity index of the SCL-90-R) $(n=396)$ and one-third of a random sample of those with scores below the 85th percentile $(n=195)$. The use of stratified samples is not uncommon in epidemiological research (Dunn et al. 1999). Altogether, seven interview waves were conducted: in 1979, 1981, 1986, 1988, 1993, 1999 and 2008. For the present analysis only data collected from 1986 onwards were used; in 1986 an interview section on mania was added to the interview. The initial allocation to the two strata did not change over the study's time span.

The analysis is presented both with the raw figures $(\mathrm{n}=475$ in the period 1986-2008) and with figures after reweighting to offset the stratification $(n=2051)$. For the reweighting, the analysis was conducted with the SAS procedure PROC SURVEYFREQ.

For the definitions of ICD-11 we have used the documents available on the internet. For the ICD-10, diagnostic criteria for research were subsequently published, distinct from of the CDDG for clinicians, (ICD-10 DCR) (World Health Organization 1993). These imposed both symptom numbers and duration cut-offs, narrowing the differences between the ICD and DSM-IV. We applied ICD-10 DCR definitions in our analyses of ICD-10 but this approach was not extended to ICD-11, as there is no indication that diagnostic research criteria will be produced for this latest revision.

\section{Bipolar disorders in ICD-11}

The mood disorders section in ICD-11 has been reorganized, opening with the description of mood episodes (depressive, manic, mixed and hypomanic), which are not coded. Codes are ascribed to disorders, which are diagnosed on the basis of the pattern of a patient's mood episodes over time. Moreover, in the bipolar and related disorders grouping newer research led to the subdivision of bipolar disorder into types I and II, based on the distinction between mania and hypomania (Reed et al. 2019). This is in line with DSM-5.

\section{Mania as a diagnosis}

Historically bipolar disorders (BP) included mania, BP-I, BP-II, hypomania and cyclothymic disorders. The international diagnostic manuals do not reflect the full affective spectrum. In none of them does mania have the status of a separate disorder. Since ICD-10 a manic episode has been codable only within mood disorders. Those with mania/a manic episode are diagnosed as having bipolar-I disorder. ICD-11 continues this tradition, which is in line with the successive versions of the DSM, including DSM-5. This must nonetheless be considered a loss in both clinical and research terms. There is growing evidence from epidemiological, clinical and genetic studies that unipolar mania exists as a distinct disorder (Merikangas et al. 2014; Baek et al. 2014; Angst and Grobler 2015). A recent analysis of data merged from seven epidemiological studies of adults found BP-I (mania with major depressive disorder) in 323 subjects and pure mania in 109 , a relatively rare but separate diagnosis (Angst et al. 2018).

\section{Major change in the definitions of manic and hypomanic syndromes and episodes in ICD-11 and DSM-5}

The definitions of manic and hypomanic syndromes and episodes in the two manuals are now almost identical as regards entry criteria, duration, hospitalization, and the presence or absence of psychotic features and impairment in social and occupational functioning, albeit with the dissimilarities referred to above (essential features vs. lettered entry criteria, etc.).

All manic and hypomanic episodes in ICD-11 require as defining features:

1. euphoria, irritability or expansiveness, and, increased activity or subjective experience of increased energy

2. plus "several "(ICD-11), three or more (DSM 5) of the following 7 symptoms:

1. increased talkativeness or pressured speech,

2. flight of ideas,

3. increased self-esteem or grandiosity,

4. decreased need of sleep,

5. distractibility,

6. impulsive reckless behaviour,

7. increase in sexual drive, sociability or goaldirected activity.

Thus, a diagnosis of bipolar mood disorders in both ICD-11 and DSM-5 now requires as an essential entry feature not only the presence of elated/euphoric, expansive or irritable mood but in addition, in all cases, increased activity/energy; this is in contrast to both 
ICD-10 and DSM-IV TR (American Psychiatric Association 2000) which required as criterion A only the presence of mood changes. This development is not without problems. Earlier, we illustrated the consequences of this important conceptual change, as introduced by DSM5, with data from the Bridge Study. 810 of 3618 (22.5\%) patients with Major Depression manifested only one mood criterion for bipolarity (elated or irritable). Following DSM-IV criteria those patients were diagnosed with bipolar disorders, whereas according to DSM-5 they lost their bipolarity and were re-diagnosed as having major depressive disorder (Angst et al. 2014).

\section{Manic and hypomanic episodes in ICD-11 compared to DSM-5}

DSM-5 defines manic episodes and hypomanic episodes slightly more restrictively (as had the ICD-10 DCR) in that for cases with mood irritability only (without euphoria) it requires 4 rather than 3 of the 7 symptoms for a diagnosis; ICD-11 does not single out irritability in this way.

Similarly the minimum duration of a hypomanic episode is $4+$ days in DSM-5 and "several days" in ICD-11 For the purposes of our analysis several was interpreted as $4+$ consecutive days.

One further restriction in the definition of a hypomanic episode in DSM-5 relates to changes in functioning. In DSM-5 criterion C: an unequivocal change in functioning uncharacteristic of the person, and criterion D: the disturbance in mood and the change in functioning are observable by others must be met. In ICD-11 this is less categorically expressed as the significant change in the usual range of moods and behaviour would be apparent to people who know the individual well.

\section{Exclusions}

Like DSM-5, ICD-11 excludes syndromes caused by the effects of a substance or medication, another medical condition (tumour etc.), but now allows the diagnosis of a manic or hypomanic episode if the full syndrome persists after antidepressant treatment (e.g. medication, ECT, light therapy) is discontinued and its direct effects have ceased or receded.

Causal attributions and exclusions are, however, known to be problematic and not data based.

\begin{tabular}{|c|c|c|c|c|c|}
\hline & $\begin{array}{l}\text { ICD-11 } \\
\text { Mania }\end{array}$ & Hypomania & $\begin{array}{l}\text { Manic } \\
\text { symptoms }\end{array}$ & Others & Total \\
\hline $\begin{array}{l}\text { ICD-10 } \\
\text { mania }\end{array}$ & 28 & 1 & 2 & 0 & 31 \\
\hline Hypomania & 0 & 40 & 0 & 0 & 40 \\
\hline $\begin{array}{l}\text { Manic } \\
\text { symptoms }\end{array}$ & 1 & 7 & 144 & 0 & 152 \\
\hline Others & 0 & 0 & 0 & 252 & 252 \\
\hline Total & 29 & 48 & 146 & 252 & 475 \\
\hline
\end{tabular}

\section{Comparison of diagnostic systems using data from the Zurich study: ICD-10, ICD-11 and DSM-5 ICD-11 and ICD-10: manic symptoms, hypomania and mania}

Comparing ICD-11 with ICD-10 (ICD-10 DCR) our analysis (Table 1) found a minimal reduction in the frequency of ICD-11 manic episodes $(\mathrm{N}=29)$ compared to ICD-10 (31). On the other hand ICD-11 diagnosed 48 subjects with a hypomanic episode vs. 40 by ICD-10.

Prevalence rates have to be weighted, because in the Zurich study risk cases (high scorers on the SCL-90 R) were purposely over-represented (Table 2).

\section{ICD-11 and DSM-5: manic symptoms, hypomania and mania}

ICD-11 and DSM-5 are in close agreement in the diagnosis of manic episodes (Table 3) but hypomanic episodes are far more frequently identified by ICD-11 $(\mathrm{N}=48)$ than DSM-5 $(\mathrm{N}=15)$; only 10 subjects are classified by both.

Application of ICD-11 results in prevalence of mania in $5.4 \%$, DSM-5 in $4.7 \%$. But hypomania is diagnosed by ICD-11 far more frequently in $9.9 \%$ compared to DSM-5 in $2.2 \%$. The prevalence rates are shown in Table 4.

\section{Validity of the ICD-11 diagnoses}

As validators we can provide family history (parents, siblings) and lifetime treatment for manic or depressive symptoms.

As is clear in Table 5, a positive family history $(\mathrm{FH}+)$ is strongly correlated with the diagnostic groups of mania and hypomania. Both diagnostic subgroups correlate significantly in their $\mathrm{FH}+$ for mania, suicide/attempts, alcohol abuse/dependence and anxiety/panic. But there is no association with a $\mathrm{FH}+$ for depression or smoking.

Table 6 lists percentage treatment rates for manic and depressive symptoms for ICD-11, ICD-10 and DSM5. The three diagnostic classifications show very similar 
Table 2 ICD-11 vs. ICD-10: prevalence rates, weighted (\%) with $95 \%$ confidence intervals

\begin{tabular}{llllll}
\hline & ICD-11 Mania & Hypomania & Manic symptoms & Others & Total \\
\hline ICD-10 Mania & $5.4(2.4-8.4)$ & $0.05(0.0-0.1)$ & $0.6(0.0-1.7)$ & 0 & $6.0(2.8-9.2)$ \\
Hypomania & 0 & $8.5(4.7-12.3)$ & 0 & 0 & $8.5(4.7-12.3)$ \\
Manic symptoms & $0.05(0.0-0.1)$ & $1.3(0.0-2.9)$ & $27.1(21.2-33.1)$ & 0 & $28.5(22.5-34.6)$ \\
Others & 0 & 0 & 0 & $57.0(50.3-63.7)$ & $57.0(50.3-63.7)$ \\
Total & $5.4(2.4-8.5)$ & $9.9(5.8-13.9)$ & $27.7(21.7-33.7)$ & $57.0(21.7-33.7)$ & 100 \\
\hline
\end{tabular}

Table 3 ICD-11 vs DSM-5: manic spectrum including hospitalization lifetime

\begin{tabular}{lccccc}
\hline & $\begin{array}{l}\text { ICD-11 } \\
\text { mania }\end{array}$ & Hypomania & $\begin{array}{l}\text { Manic } \\
\text { symptoms }\end{array}$ & Others & Total \\
\hline $\begin{array}{l}\text { DSM-5 } \\
\text { mania }\end{array}$ & 23 & 0 & 2 & 0 & 25 \\
Hypomania & 1 & 10 & 4 & 0 & 15 \\
$\begin{array}{l}\text { Manic } \\
\text { symptoms }\end{array}$ & 5 & 37 & 140 & 0 & 182 \\
Others & 0 & 1 & 0 & 252 & 253 \\
Total & 29 & 48 & 146 & 252 & 475 \\
\hline
\end{tabular}

validity regarding the treatment of manic symptoms but none for the treatment of depressive symptoms.

If ICD currently classifies patients who have been hospitalized for manic syndromes as having manic episodes, individuals with manic symptoms who have been treated could reasonably be diagnosed as hypomanic. In Table 6 we show this to be the case for 4 of 149 subjects $(2.7 \%)$, who, if added to the subjects with hypomania, would increase their number from 48 to 52 . The prevalence rate would correspondingly increase from 9.9 to $10.1 \%$. Of course further research into this approach is needed.

In order to test the hypothesis of a continuum from normal to pathological, one might also look at recurrent brief hypomania among those with manic symptoms (Angst 1997). It is present in 37 subjects, with a prevalence of $7.8 \%$. Cumulatively $23.38 \%$ of individuals manifested manic, hypomanic or brief hypomanic episodes.

\section{Conclusions}

Compared to ICD-10 and DSM-5, the current ICD-11 definition of hypomanic episodes represents important progress. Hypomanic episodes will be diagnosed twice as frequently as manic episodes. From a clinical point

Table 4 ICD-11 vs. DSM-5: prevalence rates, weighted (\%) with 95\% confidence intervals

\begin{tabular}{|c|c|c|c|c|c|}
\hline & ICD-11 mania & Hypomania & Manic symptoms & Others & Total \\
\hline DSM-5 mania & $4.1(1.5-6.8)$ & 0 & $0.6(0.0-1.7)$ & 0 & $4.7(1.9-7.6)$ \\
\hline Hypomania & $0.05(0.0-0.1)$ & $1.5(3.0-15.1)$ & $0.7(0.0-1.8)$ & 0 & $2.2(0.3-4.1)$ \\
\hline Manic symptoms & $1.2(0.0-2.8)$ & $8.3(4.6-12.1)$ & $26.4(20.5-32.3)$ & 0 & $36.0(29.5-42.7)$ \\
\hline Others & 0 & $0.05(0.0-0.1)$ & 0 & $57.0(50.3-63.7)$ & $57.0(50.4-63.7)$ \\
\hline Total & $5.4(2.4-8.5)$ & $9.9(5.8-13.9)$ & $27.7(21.7-33.7)$ & $57.0(50.3-63.7)$ & 100 \\
\hline
\end{tabular}

Table 5 ICD-11 mania: family history (parents and siblings)

\begin{tabular}{|c|c|c|c|c|c|}
\hline ICD-11 & Mania (29) \% & Hypomania (48) \% & $\begin{array}{l}\text { Manic symptoms } \\
(146) \%\end{array}$ & Others (252) \% & $\begin{array}{l}\text { Chi square } \\
\text { P }\end{array}$ \\
\hline \multicolumn{6}{|l|}{ Family history } \\
\hline Mania & 24.1 & 18.7 & 8.9 & 3.2 & $<.0001$ \\
\hline Depression & 62.1 & 58.3 & 57.5 & 49.6 & $<.284$ \\
\hline Suicidality & 37.9 & 12.5 & 18.5 & 16.3 & $<.025$ \\
\hline Anxiety/panic & 58.6 & 47.9 & 32.2 & 24.6 & $<.0001$ \\
\hline Alcohol abuse & 17.2 & 12.5 & 24.7 & 11.5 & $<.0061$ \\
\hline Smoking & 72.4 & 72.3 & 79.3 & 71.1 & $<.389$ \\
\hline
\end{tabular}

Probands' responses only; consent to interview relatives was not given 
Table 6 Lifetime treatment for manic or depressive symptoms

\begin{tabular}{lllll}
\hline & Mania & Hypomania & $\begin{array}{l}\text { Manic } \\
\text { symptoms }\end{array}$ & $\mathbf{P}$ \\
\hline \multicolumn{2}{l}{ \%Treatment } & manic symptoms & & \\
ICD.11 & 26.7 & 12.5 & $2.7^{\mathrm{a}}$ & .0001 \\
ICD-10 & 25.8 & 15.0 & 2.6 & .0001 \\
DSM-5 & 32.0 & 13.3 & 4.4 & .0001 \\
\% Treatment depr. symptoms & & \\
ICD.11 & 70.0 & 56.2 & 53.7 & .259 \\
ICD-10 & 67.7 & 57.5 & 53.9 & .365 \\
DSM-5 & 64.0 & 60.0 & 54.9 & .663 \\
\hline
\end{tabular}

a 4 of 149 subjects were treated as out-patients

of view it makes sense that the milder condition should occur more often than the severe one. This also means that bipolar-II disorder will become a more common diagnosis. It should be remembered that hypomanic episodes in terms of their social and subjective consequences are not always undesirable. They can be associated with an increased work capacity and heightened creativity. Transcultural research is needed into whether out-patient treatment should be included as a criterion for a diagnosis of hypomania, in parallel with the hospitalization criterion for a manic episode. Finally, ICD-11 allows greater scope for the exercise of clinical judgment, which is an important strength of this classification system.

\section{Acknowledgements}

Not applicable.

\section{Authors' contributions}

JA drafted the manuscript and conducted all the statistical analyses. WR participated in the critical revision of the manuscript. VAG revised the statistical results. All authors read and approved the final manuscript.

\section{Funding}

This work was supported by Grant Nos 3200-050881.97/1 and 32-50881.97 of the Swiss National Science Foundation.

\section{Availability of data and materials}

Not available.

\section{Ethics approval and consent to participate}

The authors assert that all procedures contributing to this work comply with the ethical standards of the relevant national and institutional committees on human experimentation and with the Helsinki Declaration of 1975, as revised in 2008. The project received prior approval (1978) from the Ethical Committee of the Zurich University Psychiatric Hospital.

\section{Competing interests}

The authors declare that they have no competing interests.

\section{Author details}

${ }^{1}$ Department of Psychiatry, Psychotherapy and Psychosomatics, Psychiatric Hospital, University of Zurich, Zurich, Switzerland. ${ }^{2}$ Institute of Psychiatry,
Laboratory of Neuroscience (LIM 27), University of São Paulo, São Paulo, Brazil. ${ }^{3}$ Department of Psychiatry and Psychotherapy, Charité University Medicine, Berlin, Germany.

Received: 4 September 2019 Accepted: 28 October 2019 Published online: 20 January 2020

\section{References}

American Psychiatric Association. Diagnostic and statistical manual of mental disorders: DSM-IV-TR. 4th ed. Washington DC: American Psychiatric Association; 2000.

American Psychiatric Association. Diagnostic and statistical manual of mental disorders: DSM-5 ${ }^{\mathrm{TM}}$. 5th ed. Arlington: American Psychiatric Association; 2013.

Angst J. Recurrent brief psychiatric syndromes: hypomania, depression, anxiety and neurasthenia. In: Judd LL, Saletu B, Filip V, editors. Basic and clinical science of mental and addictive disorders. Basel Freiburg Paris: Karger; 1997. p. 33-8.

Angst J, Grobler C. Unipolar mania: a necessary diagnostic concept. Eur Arch Psychiatry Clin Neurosci. 2015;265:273-80.

Angst J, Bowden CL, Azorin J, Perugi G, Vieta E, Young AH, editors. From DSMIV to DSM-5: some changes in major mood disorders in the bridge study (abstract). In: XVI World Congress of Psychiatry. Madrid, Spain, September 14-18, 2014: Abstracts Book Oral \& Poster Communications.

Angst J, Paksarian D, Cui L, Merikangas KR, Hengartner MP, Ajdacic-Gross V, Rössler W. The epidemiology of common mental disorders from age 20 to 50: results from the prospective Zurich Cohort Study. Epidemiol Psychiatr Sci. 2016;25:24-32.

Angst J, Rössler W, Ajdacic-Gross V, Angst F, Wittchen HU, Lieb R, Beesdo-Baum K, Asselmann E, Merikangas KR, Cui L, Andrade LH, Viana MC, Lamers F, Penninx BW, de Azevedo-Cardoso T, Jansen K, Dias-de-Mattos Souza L, Azevedo-da-Silva R, Kapczinski F, Grobler C, Gholam-Rezaee M, Preisig M, Vandeleur C. Differences between unipolar mania and bipolar-I disorder: evidence from nine epidemiological studies. Bipolar Disord. 2018. https:// doi.org/10.1111/bdi.12732.

Baek JH, Eisner LR, Nierenberg AA. Epidemiology and course of unipolar mania: results from the national epidemiologic survey on alcohol and related conditions (NESARC). Depress Anxiety. 2014;31:746-55. https:// doi.org/10.1002/da.22261.

Derogatis LR. SCL-90. Administration, scoring and procedures manual-I for the $R$ (revised) version and other instruments of the Psychopathology Rating Scale Series. Baltimore: Johns Hopkins University School of Medicine; 1977.

Dunn G, Pickles A, Tansella M, Vazquez-Barquero J-L. Two-phase epidemiological surveys in psychiatry. Br J Psychiatry. 1999;174:95-100.

Merikangas KR, Cui L, Heaton L, Nakamura E, Roca C, Ding J, Qin H, Guo W, Yao-Shugart Y, Zarate C, Angst J. Independence of familial transmission of mania and depression: results of the NIMH family study of affective spectrum disorders. Mol Psychiatry. 2014;19:214-9.

Reed GM, First MB, Kogan CS, Hyman SE, Gureje O, Gaebel W, Maj M, Stein DJ, Maercker A, Tyrer P, Claudino A, Garralda E, Salvador-Carulla L, Ray R, Saunders JB, Dua T, Poznyak V, Medina-Mora ME, Pike KM, Ayuso-Mateos JL, Kanba S, Keeley JW, Khoury B, Krasnov VN, Kulygina M, Lovell AM, de Jesus Mari J, Maruta T, Matsumoto C, Rebello TJ, et al. Innovations and changes in the ICD-11 classification of mental, behavioural and neurodevelopmental disorders. World Psychiatry. 2019;18:3-19. https:// doi.org/10.1002/wps.20611.

World Health Organization. The ICD-10 classification of mental and behavioural disorders. Clinical descriptions and diagnostic guidelines. Geneva: World Health Organization; 1992.

World Health Organization. The ICD-10 classification of mental and behavioural disorders. Diagnostic criteria for research. Geneva: World Health Organization; 1993.

\section{Publisher's Note}

Springer Nature remains neutral with regard to jurisdictional claims in published maps and institutional affiliations. 